\title{
Visfatin induces the apoptosis of endothelial progenitor cells via the induction of pro-inflammatory mediators through the NF-кB pathway
}

\author{
LINA SUN ${ }^{1}$, SHUCHUN CHEN ${ }^{2}$, HAINA GAO ${ }^{3}$, LUPING REN $^{2}$ and GUANGYAO SONG ${ }^{2}$ \\ ${ }^{1}$ Department of Endocrinology, The First Hospital of Qinhuangdao, Qinhuangdao, Hebei 06600; \\ ${ }^{2}$ Department of Endocrinology, Hebei General Hospital, Shijiazhuang, Hebei 050051; \\ ${ }^{3}$ Graduate Student Institute, Hebei Medical University, Shijiazhuang, Hebei 050017, P.R. China
}

Received August 1, 2016; Accepted June 13, 2017

DOI: $10.3892 / \mathrm{ijmm} .2017 .3048$

\begin{abstract}
Endothelial progenitor cells (EPCs) are an independent factor predicting cardiovascular events. Visfatin plays an important role in the pathogenesis of various metabolic disorders. In this study, we examined the effects of visfatin on the apoptosis of EPCs and the mechanisms underlying these effects. Cultured EPCs pre-treated with various concentrations of visfatin, FK866 (visfatin inhibitor) and BAY11-7085 [referred to as BAY11; nuclear factor $-\kappa \mathrm{B}(\mathrm{NF}-\kappa \mathrm{B})$ inhibitor] were used to investigate the association between visfatin and EPC apoptosis. Following treatment with visfatin for $48 \mathrm{~h}$, the EPCs exhibited a dose-dependent increase in apoptosis and an upregulated expression of Bax, caspase-3 and NF- $\kappa \mathrm{B}$ at both the mRNA and protein level, and a decreased protein expression of $\mathrm{Bcl}-2$. Compared with the untreated control group, the increase in EPC apoptosis, as well as in Bax and caspase-3 expression was significant following treatment with $150 \mathrm{ng} / \mathrm{ml}$ visfatin, which also induced a dose-dependent and significant increase in the protein expression of interleukin-6 (IL-6) and intercellular adhesion molecule-1 (ICAM-1). All the visfatin-induced effects were suppressed by pre-treatment with FK866. Pre-incubation of the EPCs with BAY11 for $1 \mathrm{~h}$ followed by treatment with
\end{abstract}

Correspondence to: Dr Shuchun Chen, Department of Endocrinology, Hebei General Hospital, 348 Heping West Road, Shijiazhuang, Hebei 050051, P.R. China

E-mail: guang6701@sina.com

Abbreviations: EPCs, endothelial progenitor cells; NF- $\kappa \mathrm{B}$, nuclear factor- $\mathrm{B}$; ICAM-1, intercellular adhesion molecule-1; IL-6, interleukin-6; Nampt, nicotinamide phosphoribosyltransferase; NAD, nicotinamide adenine dinucleotide; VCAM-1, vascular cell adhesion molecule-1; MNCs, mononuclear cells; KDR, kinase insert domain receptor; DiI-acLDL, DiI-labeled acetylated LDL; FITCLectin-UEA-1, fluorescein isothiocyanate-conjugated lectin from Ulex europaeus agglutinin; PVDF, polyvinylidene fluoride; ECL, enhanced chemiluminescence

Key words: visfatin, endothelial progenitor cells, apoptosis, inflammation visfatin $(150 \mathrm{ng} / \mathrm{ml})$ for $48 \mathrm{~h}$ also abolished visfatin-induced apoptosis; it also abolished the promoting effects of visfatin on the expression of caspase-3, Bax, ICAM-1 and IL-6, and its suppressive effects on the protein expression of Bcl-2. On the whole, our data indicate that visfatin induces EPC apoptosis by increasing the expression of pro-inflammatory mediators partly through the regulation of $\mathrm{NF}-\kappa \mathrm{B}$.

\section{Introduction}

Visfatin, also known as pre-B-cell colony-enhancing factor and nicotinamide phosphoribosyltransferase (Nampt), was originally cloned in 1994 and is a multifaceted molecule (1). As a nicotinamide adenine dinucleotide (NAD) biosynthetic enzyme, visfatin determines the activity of NAD-consuming enzymes, such as sirtuins and influences a variety of metabolic responses, prompting increasing attention in the literature.

Visfatin plays an important role in regulating insulin secretion, as it functions as an immunomodulatory cytokine and is involved in the inflammatory responses (2). Visfatin has also been implicated in the pathogenesis of various metabolic disorders, with increased plasma concentrations of visfatin reported in overweight/obese subjects, as well as in pateints with type 2 diabetes mellitus, metabolic syndrome, atherosclerosis and cardiovascular diseases (3-7). In atherosclerosis, visfatin has been implicated causatively by inducing oxidative stress and inflammation in endothelial cells, which subsequently damages vascular endothelial function (8). Visfatin also participates in the inflammatory process in rat spleen by modulating macrophages and inflammatory cytokines (9). In addition, treatment with visfatin in vitro has been shown to promote the proliferation of vascular smooth muscle cells (10) and to increase the endothelial expression of vascular cell adhesion molecule-1 (VCAM-1), intercellular adhesion molecule-1 (ICAM-1) and E-selectin, all of which are considered as biomarkers of endothelial dysfunction (11). Thus, these cell types are implicated as both the targets and cellular sources of visfatin. Finally, a pathological role for visfatin was also reported by a study showing that the administration of visfatin impairs microvascular endothelium-dependent relaxation through a mechanism involving NADPH oxidase 
stimulation (12). Despite these in vitro and in vivo data, the mechanisms underlying the function of visfatin remain controversial.

Endothelial progenitor cells (EPCs) are progenitor cells that can migrate to the peripheral circulation to differentiate into mature endothelial cells. In the case of vessel impairment or tissue ischemia, EPCs mobilize to peripheral blood circulation, specifically home in to the damaged or ischemic tissue, and then differentiate further into mature endothelial cells (13). Thus, the restoration and regeneration of endothelial cells depends not only on the proliferation and migration of mature endothelial cells, but also on the circulating EPC levels. Indeed, the decrease in the number of circulating EPCs has been used to independently predict atherosclerotic progression and poor prognosis in patients with coronary heart disease $(14,15)$. It is also known that apoptosis plays a crucial role in the loss of EPCs, with data suggesting several factors that may be associated with traditional and the disease-related risk of eliciting apoptosis in EPCs, including C-reactive protein, oxidized lowdensity lipoprotein (LDL) and interferon- $\alpha$ (16-18).

Emerging evidence has established a potential link between adipokines and vascular dysfunction, while our previous studies have correlated EPC dysfunction in obese rats with serum visfatin levels (19), with higher levels of serum visfatin and a lower level of circulating EPCs in the obese population (7). However, the specific mechanisms remain unclear, and few studies have specifically investigated visfatin and EPCs, and the related mechanisms of action. In the present study, we investigated whether visfatin plays a role in promoting EPCs apoptosis and aimed to elucidate the mechanisms underlying such effects.

\section{Materials and methods}

Isolation and culture of EPCs. This study was approved by the Ethics Committee of Hebei General Hospital. Informed consent was obtained from all subjects. Umbilical vein blood mononuclear cells (MNCs) of healthy pregnant woman donors were isolated by Ficoll density gradient centrifugation (Dakewe, Shenzhen, China). After washing with phosphate-buffered saline (PBS), the MNCs were resuspended in EGM-2MV medium (Lonza, Walkersville, MD, USA), supplemented with $20 \%$ fetal bovine serum, $1 \%$ Pen/Strep, $0.04 \%$ hydrocortisone, $0.1 \%$ heparin and $0.1 \%$ ascorbic acid in the presence of insulinlike growth factor-1 (IGF-1; $50 \mathrm{ng} / \mathrm{ml}$ ), epidermal growth factor (EGF; $10 \mathrm{ng} / \mathrm{ml}$ ), fibroblast growth factor (FGF; $50 \mathrm{ng} / \mathrm{ml}$ ), vascular endothelial growth factor (VEGF; $50 \mathrm{ng} / \mathrm{ml}$ ) and fibronectin $(10 \mu \mathrm{g} / \mathrm{ml})$. Six-well tissue culture plates pre-coated with fibronectin (Solarbio, Beijing, China) and the cells were seeded at a density of $2 \times 10^{6}$ cells $/ \mathrm{ml}$ and cultured in a $5 \% \mathrm{CO}_{2}$ incubator at $37^{\circ} \mathrm{C}$. After $48 \mathrm{~h}$ of culture, non-adherent cells were removed by washing with PBS, and EGM-2MV medium was added to each well. The medium was changed every 2 days until treatment. The cells were observed daily under an inverted microscope (TS100F; Nikon, Tokyo, Japan).

Immunophenotyping of EPCs. Immunophenotyping of cultured cells was detected by flow cytometry. Briefly, the EPCs were washed twice with PBS and incubated with EPC-specific markers for $30 \mathrm{~min}$ at $4^{\circ} \mathrm{C}$ in the dark. The following
FITC- or PE-conjugated monoclonal antibodies (mAbs) were used as EPCs markers: anti-human CD34 (555748) and anti-human CD309 (554680), also termed kinase insert domain receptor (KDR) (both from Becton-Dickinson, Franklin Lakes, NJ, USA). Isotype-matched irrelevant mAbs were used as negative controls. The cells were electronically gated according to their light scattering properties to exclude cell debris. CD309 ${ }^{+} \mathrm{CD} 34^{+}$double-positive cells were considered as EPCs. Data were detected on a FACSCanto flow cytometer (Becton-Dickinson) and analysed using SPSS 13.0 software (IBM, Armonk, NY, USA).

Uptake of Dil-acetylated low-density lipoprotein and staining for Ulex europaeus lectin. The EPCs were marked by cellular uptake of DiI-labeled acetylated LDL (DiI-ac-LDL; Molecular Probes, Eugene, OR, USA) and binding of FITC-conjugated lectin from Ulex europaeus agglutinin (FITC-Lectin-UEA-1; Sigma-Aldrich, St. Louis, MO, USA). After 10 days in culture, the attached cells were incubated with Dil-ac-LDL $(2.5 \mu \mathrm{g} / \mathrm{ml})$ in EGM-2MV medium for $3 \mathrm{~h}$ at $37^{\circ} \mathrm{C}$. The cells were then fixed with $2 \%$ paraformaldehyde for $10 \mathrm{~min}$ and incubated for $1 \mathrm{~h}$ with FITC-Lectin-UEA-1 $(10 \mu \mathrm{g} / \mathrm{ml})$. The cells were then observed under an Olympus Fluoview FV1000 laser scanning confocal microscope (OLFV-34CMXE; Olympus, Tokyo, Japan). Orange cells positive for both DiI-ac-LDL and FITCLectin-UEA-1 were identified as EPCs.

Treatment of EPCs with visfatin. After being cultured for 7 days, the adherent EPCs were serum-starved for $24 \mathrm{~h}$, and then incubated with human recombinant visfatin (Peprotech, Rocky Hill, NJ, USA) at various concentrations (0, 50, 100 and $150 \mathrm{ng} / \mathrm{ml}$ ) for $48 \mathrm{~h}$. In some experiments, the EPCs were pretreated with visfatin inhibitor (FK866, $10 \mu \mathrm{M}$; Sigma-Aldrich) or nuclear factor- $\kappa \mathrm{B}(\mathrm{NF}-\kappa \mathrm{B})$ inhibitor [BAY11-7085 (referred to as BAY11), $5 \mu \mathrm{M}$; Santa Cruz Biotechnology, Inc., Santa Cruz, CA, USA] $1 \mathrm{~h}$ prior to incubation with visfatin at various concentrations for $48 \mathrm{~h}$.

Flow cytometry. The apoptosis of the EPCs was evaluated by flow cytometry. The EPCs were fluorescently labeled by the addition of $500 \mu \mathrm{l}$ of binding buffer, $5 \mu \mathrm{l}$ of Annexin V-FITC and $5 \mu \mathrm{l}$ of propidium iodide (Miltenyi Biotec, Bergisch Gladbach, Germany). Following incubation in the dark at room temperature for $15 \mathrm{~min}$, the cells were subjected to flow cytometric analysis. A minimum of 10,000 cells in the gated region was analyzed using a BD FACSCalibur Flow Cytometer (Becton-Dickinson). The esults were presented by the percentage of total cells.

Reverse transcription-quantitative PCR (RT-qPCR). Total RNA was extracted from the EPCs using TRIzol reagent (Invitrogen, Carlsbad, CA, USA). RNA was reversetranscribed into cDNA according to the instructions of the Easy Script First Strand cDNA Synthesis Super Mix kit (TransGen Biotech, Beijing, China). Specific primers designed for the amplification of caspase-3, Bax, Bcl-2, NF- $\kappa \mathrm{B}$ and glyceraldehyde 3-phosphate dehydrogenase (GAPDH) were verified by NCBI Blast; primer sequences are listed in Table I. Reactions were carried out on an ABI PRISM 7300 PCR system (Applied Biosystems, Foster City, CA, USA) using SYBR-Green I 
Table I. Sequences of primers used for RT-qPCR.

\begin{tabular}{lll}
\hline Genes & \multicolumn{1}{c}{ Forward $\left(5^{\prime} \rightarrow 3^{\prime}\right)$} & \multicolumn{1}{c}{ Reverse $\left(5^{\prime} \rightarrow 3^{\prime}\right)$} \\
\hline GADPH & TGAACGGGAAGCTCACTGG & GCTTCACCACCTTCTTGATGTC \\
Caspase-3 & TGGACTGTGGCATTGAGAC & AATAACCAGGTGCTGTGGAGT \\
Bax & GGCTGGACATTGGACTTCCT & CCACAAAGATGGTCACGGT \\
Bcl-2 & GTGGATGACTGAGTACCTGAAC & CGCATCTCGGACCTGTG \\
NF- $\mathrm{kB}$ & CAAGGCAGCAAATAGACGAG & TGTTGAGAGTTAGCAGTGAGGC
\end{tabular}

GAPDH, glyceraldehyde 3-phosphate dehydrogenase; NF- $\mathrm{B}$, nuclear factor- $\kappa \mathrm{B}$.

GoTaq $^{\circledR}$ qPCR Master Mix (Promega, Madison, WI, USA). PCR reactions were performed in a total of $25 \mu 1$ as follows: an initial cycle at $95^{\circ} \mathrm{C}$ for $5 \mathrm{~min}$, followed by 40 cycles of $95^{\circ} \mathrm{C}$ for $15 \mathrm{sec}, 58^{\circ} \mathrm{C}$ for $20 \mathrm{sec}$ and $72^{\circ} \mathrm{C}$ for $30 \mathrm{sec}$. The gene expression was analyzed in duplicate and normalized against GAPDH. The results of each gene are expressed as relative expression using the $\Delta \mathrm{Ct}$ method.

Western blot analysis. The cells were washed twice with ice-cold PBS and cellular proteins from EPCs under various treatments were prepared with lysis buffer [1\% NP-40, $150 \mathrm{mM}$ $\mathrm{NaCl}, 50 \mathrm{mM}$ Tris (pH 8.0), $0.1 \%$ aprotinin, $0.1 \%$ leupeptin, $0.035 \%$ pepstain A and $100 \mu \mathrm{g} / \mathrm{ml}$ PMSF] supplemented with protease inhibitor cocktail tablets (Roche Diagnostics, Mannheim, Germany) and solubilized for $30 \mathrm{~min}$ at $4^{\circ} \mathrm{C}$. The samples were centrifuged at $11,600 \mathrm{x} \mathrm{g}$ for $30 \mathrm{~min}$ at $4^{\circ} \mathrm{C}$. Protein concentrations were determined via Nanojob (Thermo Fisher Scientific, Inc., Waltham, MA, USA). Protein samples were then denatured in glyceraldehyde 3-phosphate dehydrogenase (SDS) sample buffer (125 mM Tris-HCl, $\mathrm{pH} 6.8,50 \%$ glycerol, $2 \%$ SDS, $5 \% \beta$-mercaptoethanol and $0.01 \%$ bromophenol blue) for $10 \mathrm{~min}$ at $100^{\circ} \mathrm{C}$. Equal amounts of proteins were separated by $10 \%$ SDS-PAGE and transferred onto polyvinylidene fluoride (PVDF) membranes (Millipore, Billerica, MA, USA). Subsequently, 5\% non-fat milk in Tris-buffered saline was used for blocking for $4 \mathrm{~h}$ at room temperature. After blocking, the membranes were incubated overnight at $4^{\circ} \mathrm{C}$ with appropriately diluted rabbit anti-human primary antibodies to caspase-3 (sc-2048; Santa Cruz Biotechnology, Inc.), Bax (50599-2-Ig; Proteintech, Chicago, IL, USA), Bcl-2 (2870; Cell Signaling Technology, Danvers, MA, USA), NF-кB (\#21013; Signalway Antibody, Baltimore, MD, USA), ICAM-1 (ab53013) and interleukin (IL)-6 (ab32530) (both from Abcam, Cambridge, MA, USA), or mouse anti-human $\beta$-actin (66009-1-Ig; Proteintech), followed by incubation with the relevant secondary antibodies [caspase-3, Bax, Bcl-2, NF-кB, ICAM, IL-6: anti-rabbit IgG (L3012-1); $\beta$-actin: anti-mouse IgG (L3032-2); all from Signalway Antibody] for $2 \mathrm{~h}$ at room temperature. The immunoreactive proteins were visualized by the enhanced chemiluminescence (ECL) detection system. $\beta$-actin served as an internal control protein.

Statistical analysis. All experiments were repeated at least 3 times. Data are presented as the means \pm SD and were analyzed using the SPSS statistical package (SPSS 13.0; IBM). Data were analyzed by homogeneity testing for variance.
Statistical significance was determined by ANOVA (post-hoc used Student-Newman-Keuls test) for comparison of normally distributed data with homogeneous variance relevant groups. P-values $<0.05$ were considered to indicate statistically significant differences.

\section{Results}

Culture of EPCs. Newly isolated umbilical vein blood MNCs were round in shape when suspended in medium (Fig. 1A). After $48 \mathrm{~h}$ of plating, the cells were partly attached (Fig. 1B), with the adherent cells gradually elongating into a spindle shape (Fig. 1C). At 7-10 days after plating, the adherent cells grew as colonies. A colony of EPCs was defined as a central core of round cells with elongated sprouting cells at the periphery (Fig. 1D). The cells were round, triangle, oval or irregular. After 10 days, the cultured EPCs were linearly grown.

Immunophenotyping of EPCs. By flow cytometry, $\mathrm{CD} 309^{+} \mathrm{CD} 34^{+}$ double-positive cells were determined as EPCs (Fig. 2).

Uptake of Dil-ac-LDL and staining for FITC-Lectin-UEA-1. Following the uptake of Dil-ac-LDL and the binding of FITC-Lectin-UEA-1, double-stained EPCs were observed under a laser scanning confocal microscope (Fig. 3).

Visfatin induces the apoptosis of EPCs. Recombinant human visfatin induced a dose-dependent and significant increase in EPC apoptosis, and this effect was completely abrogated by pre-treatment with FK866 (a visfatin inhibitor) (Fig. 4A). As expected, visfatin significantly increased the expression levels of cleaved caspase- 3 in a dose-dependent manner at both the mRNA and protein level, and pre-treatment with FK866 markedly suppressed the increased expression of cleaved caspase-3 (Fig. 4B and C, and Fig. 5). The Bax/Bcl-2 expression ratio is critical for the induction of apoptosis; thus, we examined the expression of Bax and Bcl-2 in EPCs by both RT-qPCR and western blot analysis. Following treatment with visfatin, Bax expression was significantly upregulated at both the mRNA and protein level; however, the protein expression of Bcl-2 was decreased in a dose-dependent manner $(\mathrm{P}>0.05)$; these effects were all abolished by pre-treatment with FK866 (Figs. 4 and 5). The mRNA expression of Bcl-2 in the EPCs exhibited no statistically significant change, although there was a decreased trend following treatment with visfatin. 

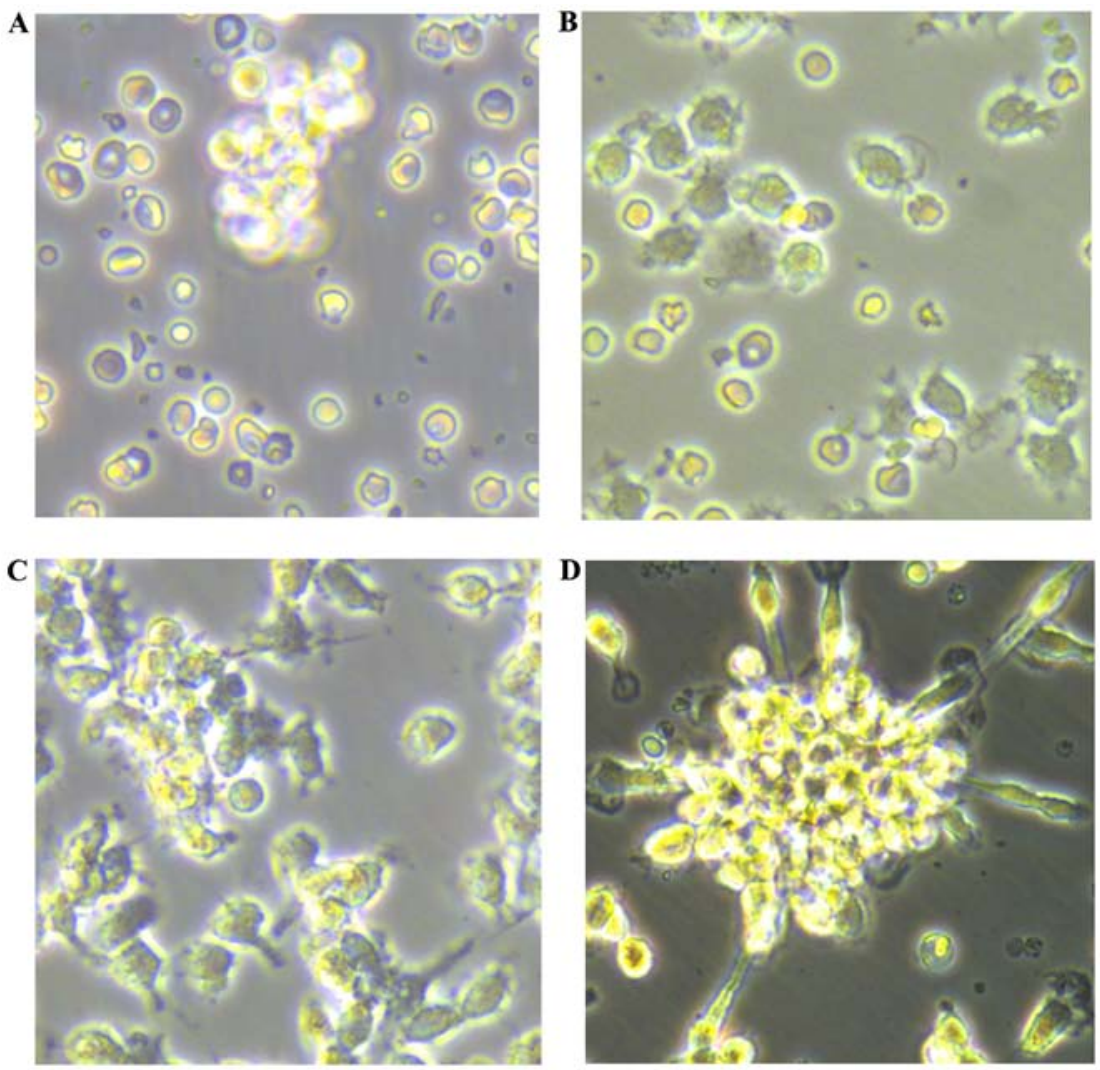

Figure 1. Culture of umbilical vein blood mononuclear cells (MNCs). Umbilical vein blood MNCs were isolated and cultured from healthy pregnant woman. Morphology of MNCs under an inverted microscope. Isolated MNCs: (A) newly isolated, after culture for (B) $48 \mathrm{~h}$ (x400 magnification), (C) 7 days (x400 magnification), (D) 10 days (x400 magnification).
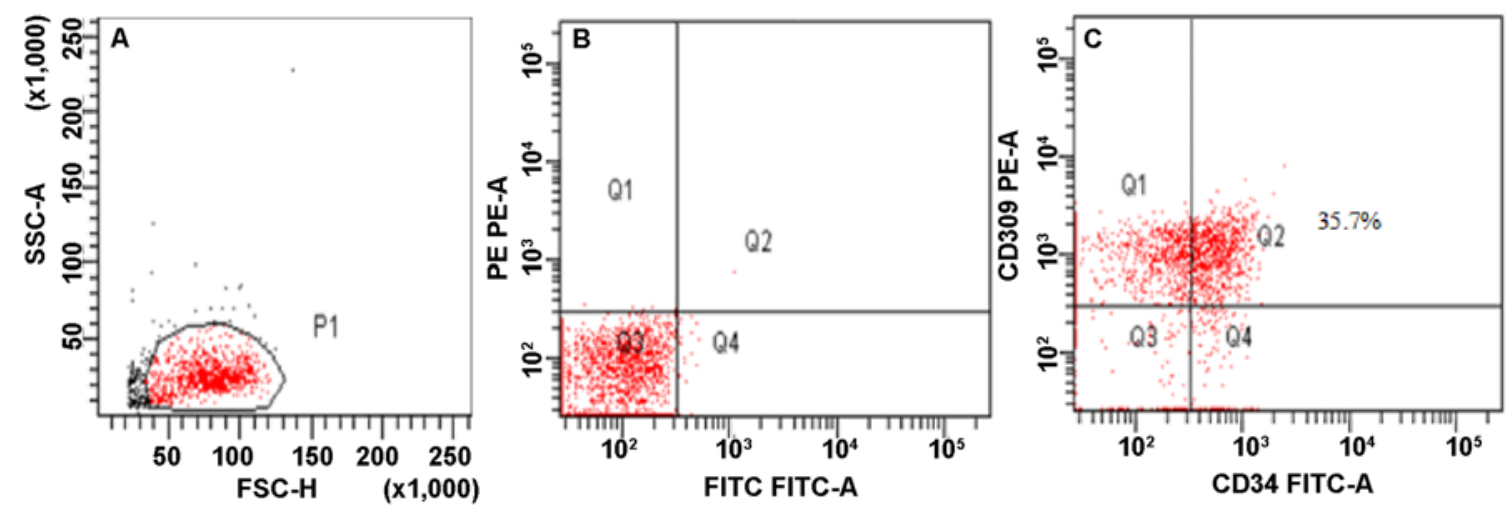

Figure 2. Immunophenotyping of cultured cells was detected by flow cytometry. (A) Gate for MNCs. (B) Negative controls of isotype-matched irrelevant mAbs. (C) $\mathrm{CD} 309^{+} \mathrm{CD} 34^{+}$double-positive cells were determined as EPCs.
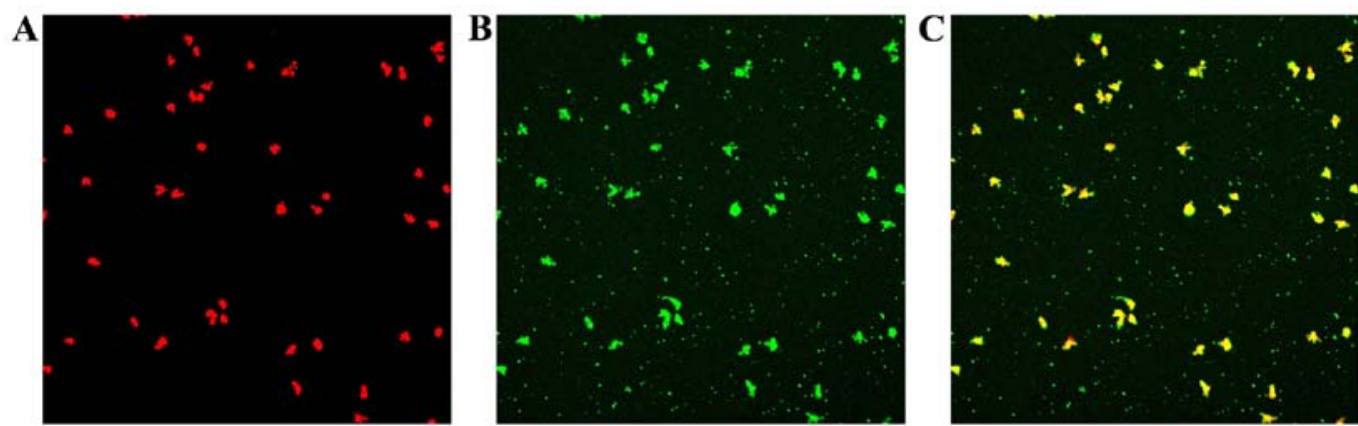

Figure 3. Endothelial progenitor cells (EPCs) were characterized by the cellular uptake of DiI-labeled acetylated low-density lipoprotein (LDL) and binding of fluorescein isothiocy-anate-conjugated lectin from Ulex europaeus agglutinin. (A) DIL-Ac-LDL uptaken by EPCs (red); (B) FITC-Lectin-UEA-1 combined by EPCs (green); (C) EPCs stained with DIL-Ac-LDL and FITC-Lectin-UEA-1 (orange). 
A
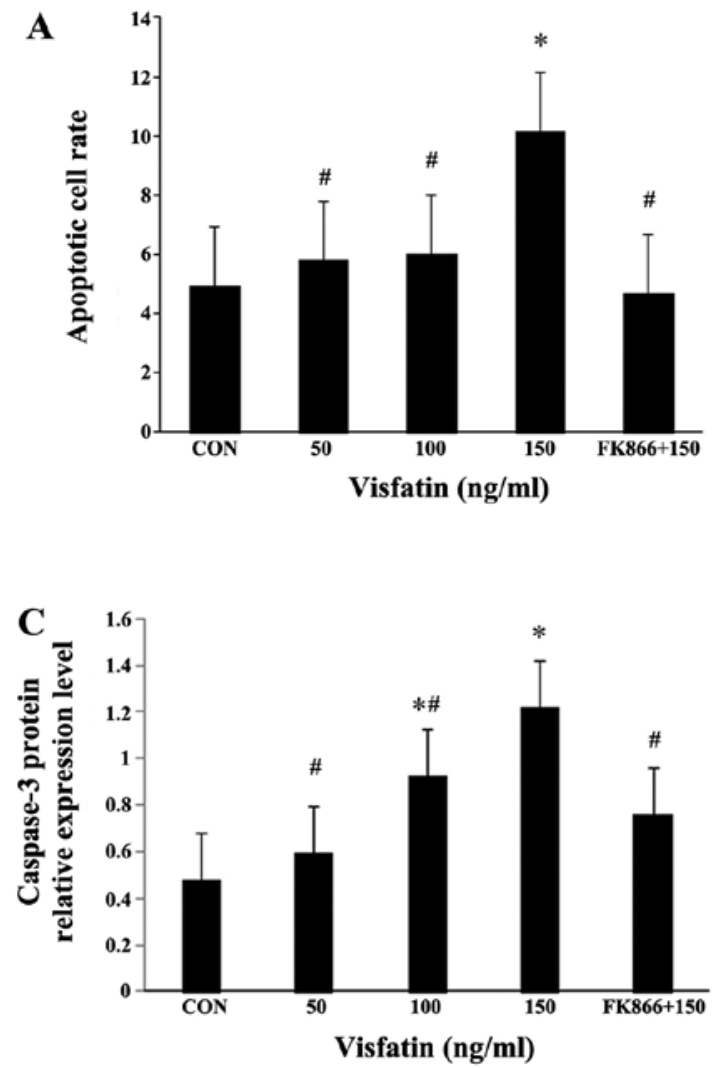

B
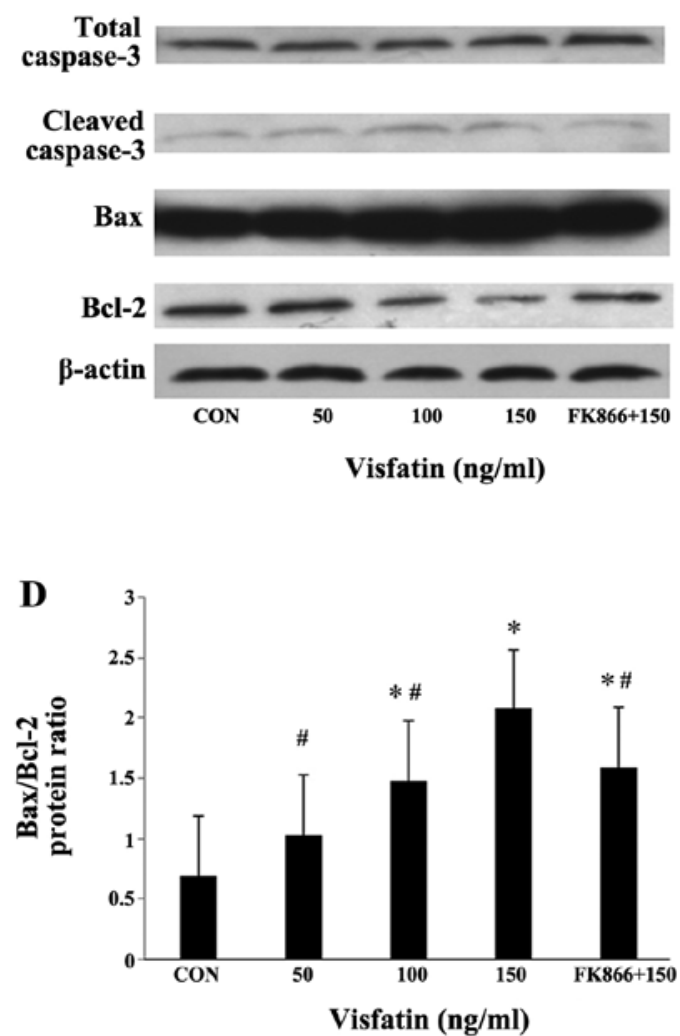

Figure 4. Effect of visfatin on endothelial progenitor cell (EPC) apoptosis. (A) EPCs were treated with visfatin (0-150 ng/ml) for $48 \mathrm{~h}$ in the presence or absence of visfatin inhibitor (FK866, $10 \mu \mathrm{M})$. Apoptotic cells were determined by flow cytometry. The apoptotic EPCs are presented by the percentage of total cells. Dose-dependent induction of apoptosis in EPCs by visfatin in the presence or absence of FK866. (B-D) Effects of visfatin on the expression of apoptosis-related proteins (caspase-3, Bax and Bcl-2), as determined by western blot analysis. Data are presented as fold change relative to $\beta$-actin. ${ }^{*} \mathrm{P}<0.05$ vs. CON (no treatment); ${ }^{\#} \mathrm{P}<0.05$ vs. $150 \mathrm{ng} / \mathrm{ml}$ visfatin. Values represent the means \pm standard deviation.
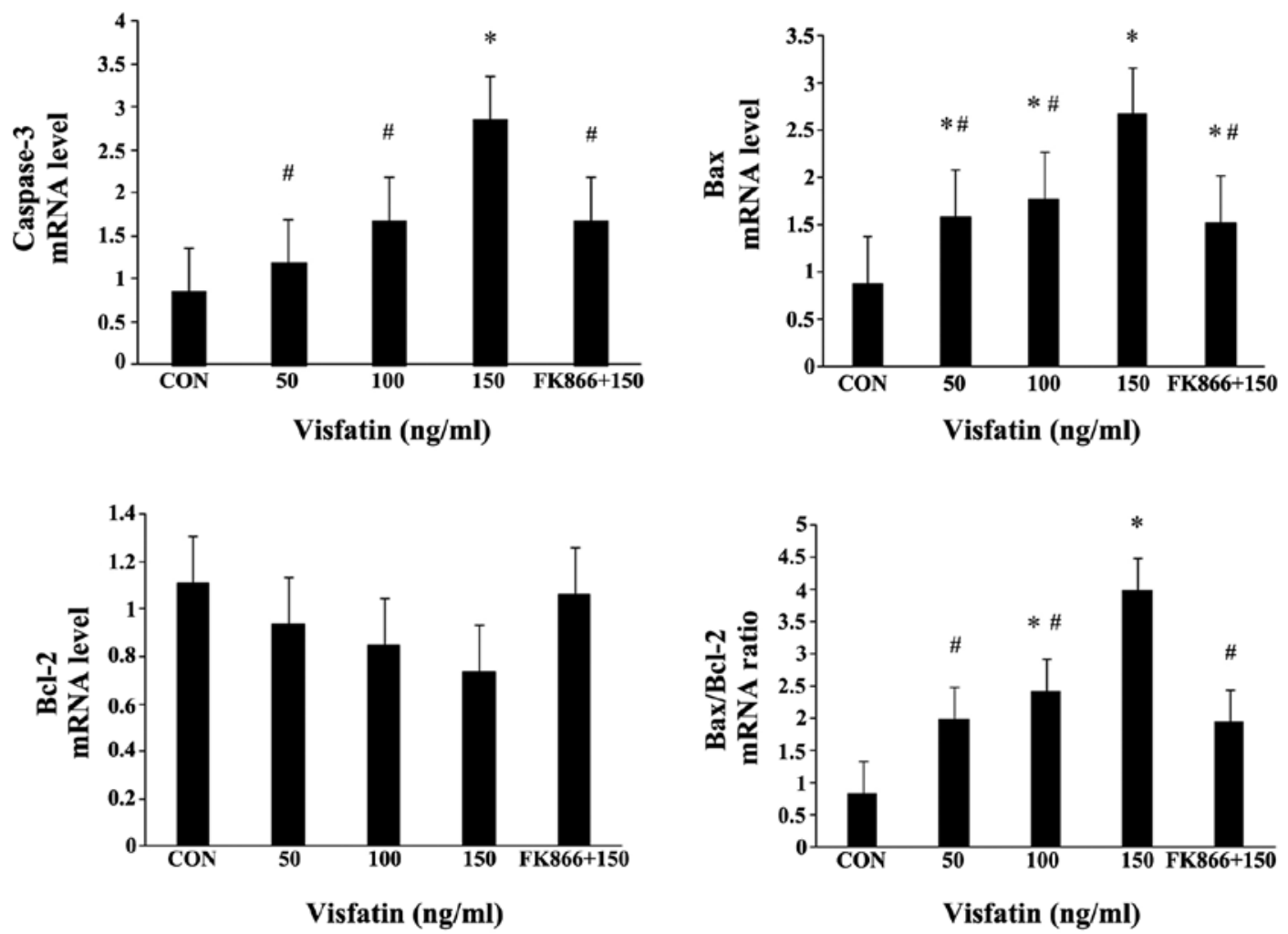

Figure 5. mRNA expression levels of caspase-3, Bax, Bcl-2 and Bax/Bcl-2 ratio in endothelial progenitor cells (EPCs) treated with visfatin in the presence or absence of FK866. RT-qPCR was performed to determine the mRNA expression levels. ${ }^{*} \mathrm{P}<0.05$ vs. CON (no treatment); ${ }^{*} \mathrm{P}<0.05$ vs. 150 ng/ml visfatin. Values represent the means \pm standard deviation. 

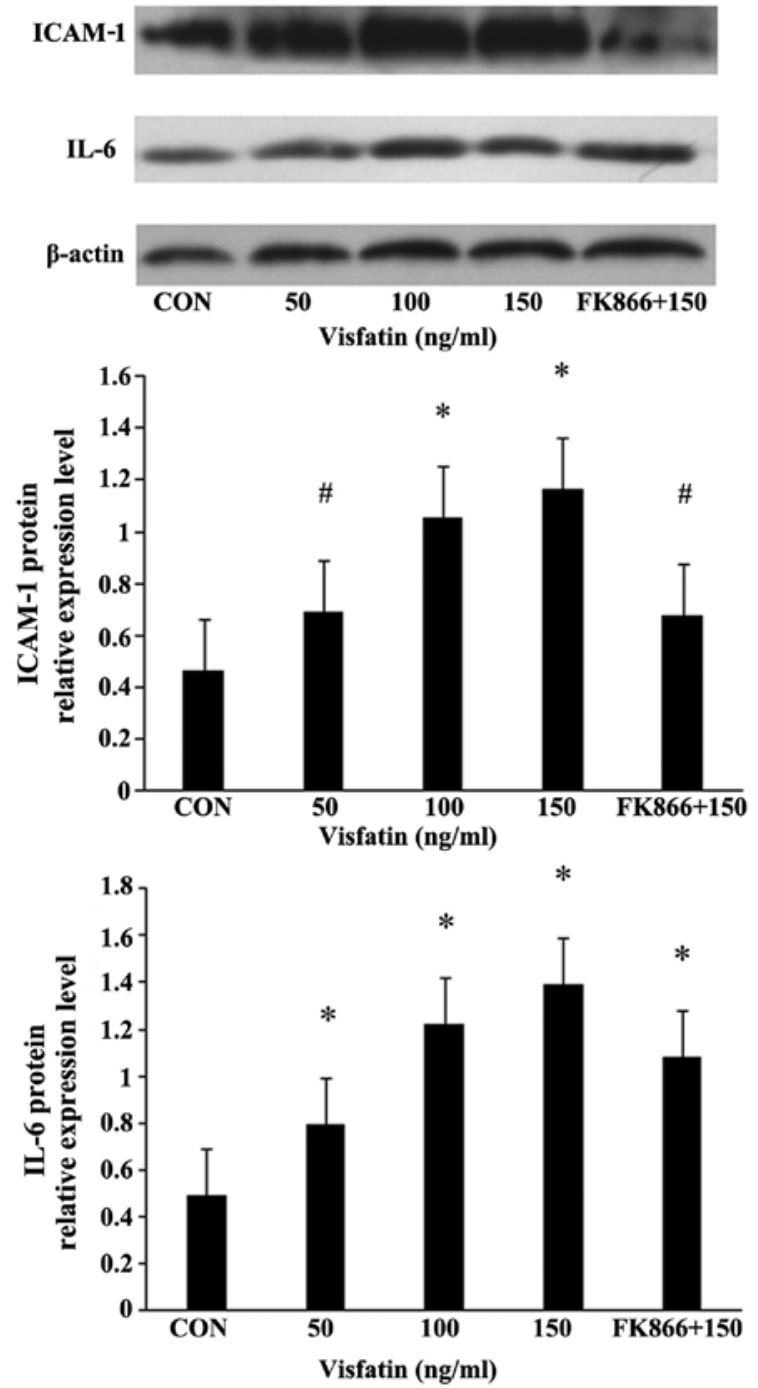

Figure 6. Visfatin-induced intercellular adhesion molecule-1 (ICAM-1) and interleukin-6 (IL-6) production in endothelial progenitor cells (EPCs). EPCs were treated with visfatin $(0-150 \mathrm{ng} / \mathrm{ml})$ for $48 \mathrm{~h}$ in the presence or absence of visfatin inhibitor (FK866, $10 \mu \mathrm{M})$. The protein expression levels of ICAM-1 and IL-6 were measured by western blot analysis. " $\mathrm{P}<0.05$ vs. CON (no treatment); ${ }^{\text {"}} \mathrm{P}<0.05 \mathrm{vs} .150 \mathrm{ng} / \mathrm{ml}$ visfatin. Values represent the means \pm standard deviation.

As a result, the ratio of $\mathrm{Bax} / \mathrm{Bcl}-2$ expression was markedly augmented in the EPCs (Figs. 4 and 5).

Pro-inflammatory mediators are involved in the apoptosis of EPCs induced by visfatin. Treatment of the EPCs with various concentrations of visfatin resulted in a dose-dependent and significant increase in the protein expression of ICAM-1 and IL-6, as determined by western blot analysis (Fig. 6). FK866 suppressed these upregulatory effects, indicating the involvement of pro-inflammatory mediators in the apoptosis of EPCs induced by visfatin.

$N F-\kappa B$ mediates visfatin-induced EPC apoptosis. Compared with the EPCs not incubated with visfatin, the expression of $\mathrm{NF}-\mathrm{\kappa B}$ in the EPCs following treatment with various concentrations of visfatin increased in a significant and dose-dependent manner at both the mRNA and protein level, an effect that was inhibited by pre-treatment with FK866 (Fig. 7).
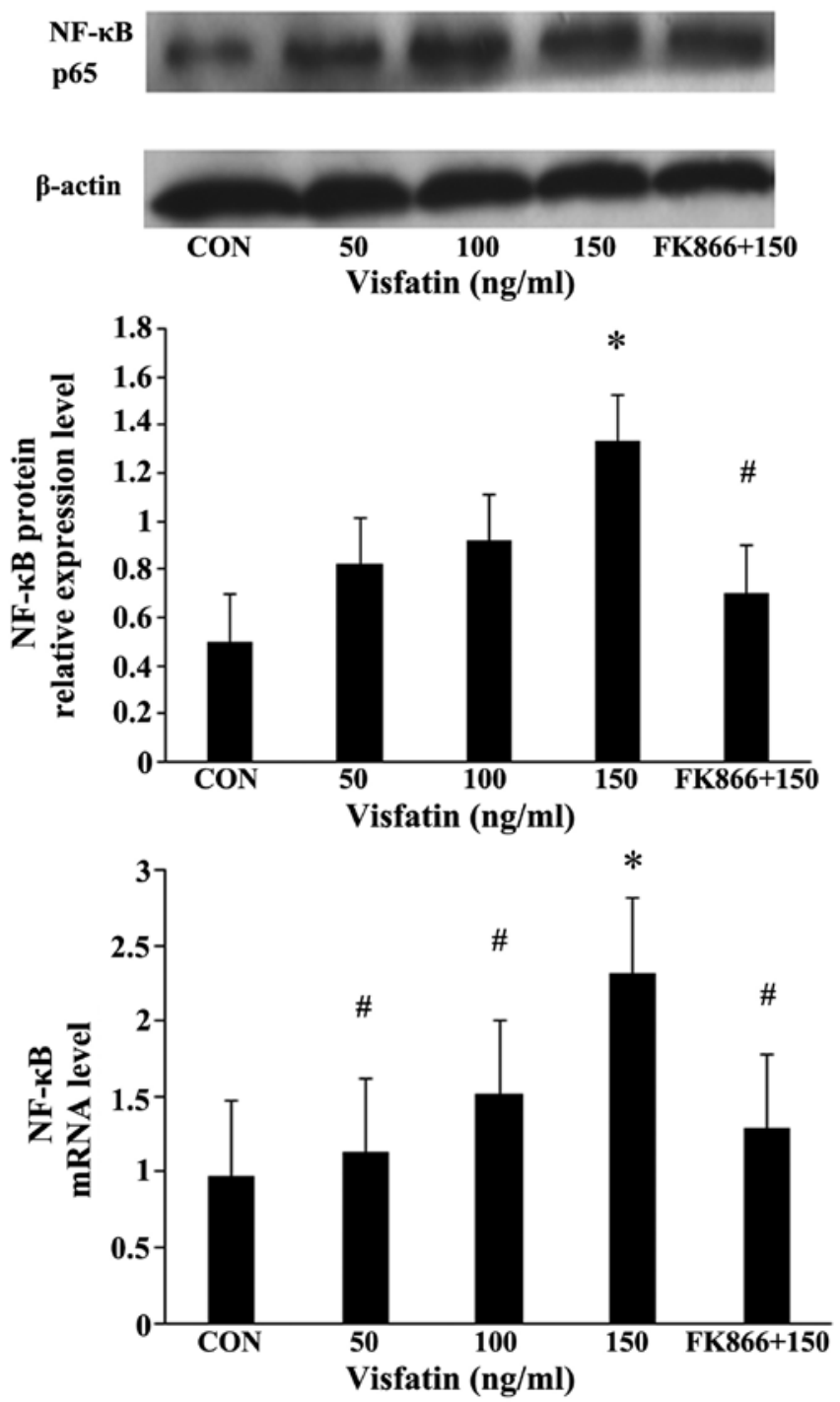

Figure 7. Nuclear factor- $\kappa \mathrm{B}(\mathrm{NF}-\kappa \mathrm{B})$ mediates visfatin-induced endothelial progenitor cell (EPC) apoptosis. Activation of NF- $\mathrm{BB}$ p65 in visfatin-treated EPCs. The expression of NF- $\kappa \mathrm{B}$ was determined by RT-qPCR and western blot analysis. ${ }^{*} \mathrm{P}<0.05$ vs. $\mathrm{CON}$ (no treatment); ${ }^{~} \mathrm{P}<0.05$ vs. $150 \mathrm{ng} / \mathrm{ml}$ visfatin. Values represent the means \pm standard deviation.

The EPCs were additionally pre-incubated with NF- $\kappa \mathrm{B}$ inhibitor (BAY11-7085, $5 \mu \mathrm{M}$ ) for $1 \mathrm{~h}$, and then treated with visfatin $(150 \mathrm{ng} / \mathrm{ml})$ for $48 \mathrm{~h}$. Compared with the visfatin-alonetreated group, BAY11 significantly diminished the increase in EPC apoptosis induced by visfatin. In addition, the increased expression of caspase- 3 and Bax, and the decreased expression of Bcl-2 were all abolished in the BAY11-treated cells (Fig. 8), suggesting that NF- $\kappa \mathrm{B}$ may mediate visfatin-induced EPC apoptosis. Moreover, BAY11 also abolished the promoting effects of visfatin on the protein expression of ICAM-1 and IL-6 in the EPCs (Fig. 9), indicating that visfatin promotes EPC apoptosis by regulating ICAM- 1 and IL- 6 expression through $\mathrm{NF}-\mathrm{\kappa B}$.

\section{Discussion}

In the present study, we provide evidence that visfatin promotes the apoptosis of EPCs, as determined by flow cytometry, and 

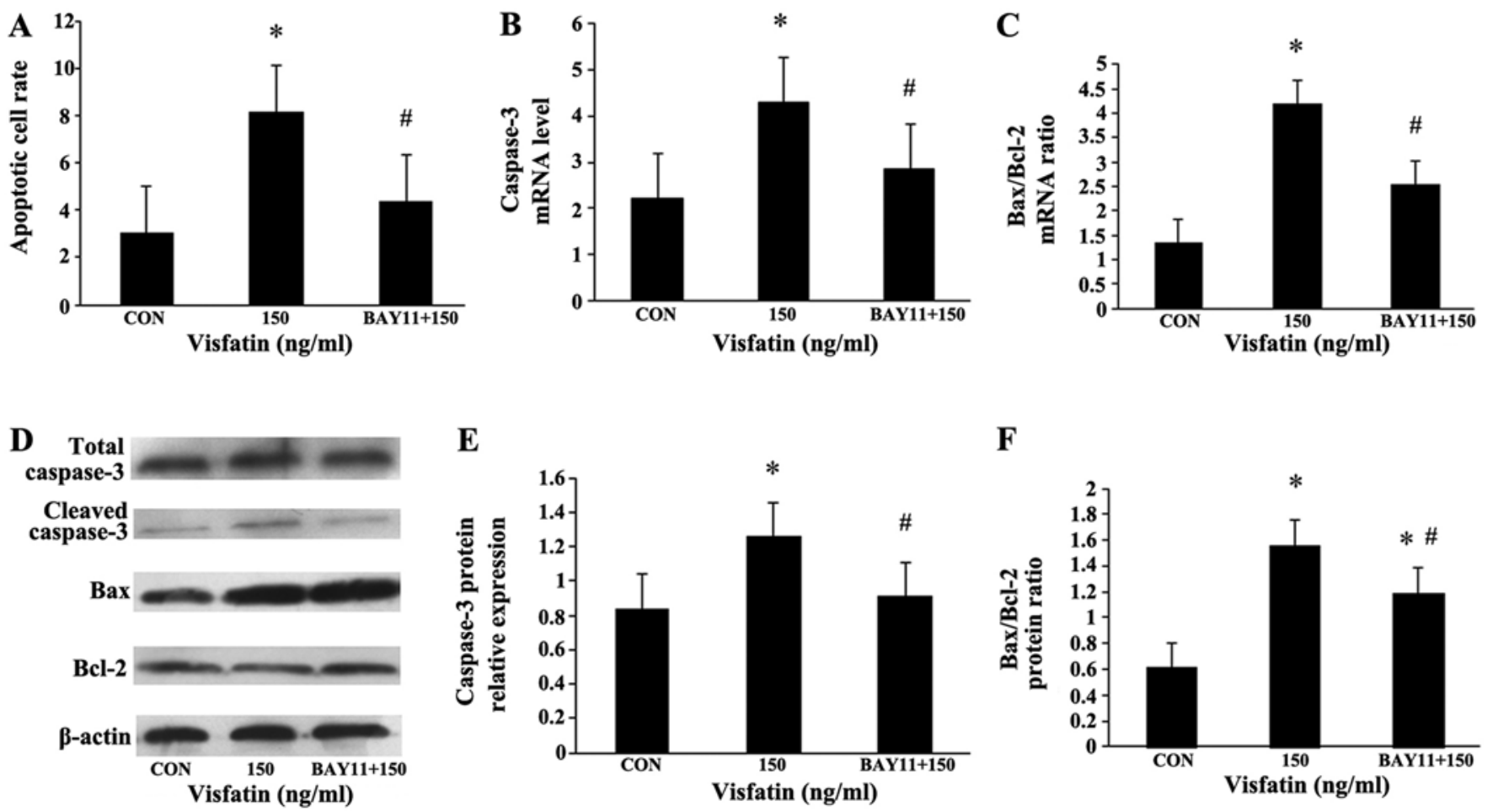

Figure 8. Inhibition of endothelial progenitor cell (EPC) apoptosis and apoptosis-related proteins by BAY11-7085. EPCs were pre-incubated with BAY11 (5 $\mu \mathrm{M})$ for $1 \mathrm{~h}$, and then incubated with $150 \mathrm{ng} / \mathrm{ml}$ visfatin for $48 \mathrm{~h}$. (A) Apoptotic cells were determined by flow cytometry. (B and C) mRNA expression levels of caspase-3 and Bax/Bcl-2 ratio in EPCs treated with visfatin in the presence or absence of BAY11. RT-qPCR was performed to determine the mRNA expression levels. (D-F) Effects of visfatin on the expression of apoptosis-related proteins, as determined by western blot analysis. Data are presented as a fold-change relative to $\beta$-actin. ${ }^{*} \mathrm{P}<0.05$ vs. $\mathrm{CON}$ (no treatment); ${ }^{\text {}} \mathrm{P}<0.05$ vs. $150 \mathrm{ng} / \mathrm{ml}$ visfatin. Values represent the means \pm standard deviation.
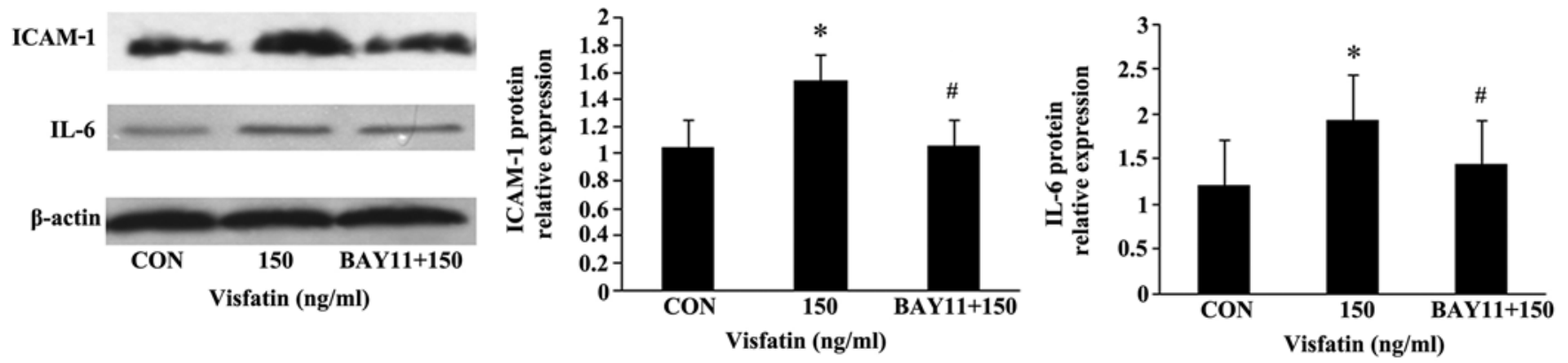

Figure 9. Downregulation of intercellular adhesion molecule-1 (ICAM-1) and interleukin-6 (IL-6) protein expression in endothelial progenitor cells (EPCs) pre-treated with BAY11-7085, as determined by western blot analysis. ${ }^{*} \mathrm{P}<0.05$ vs. CON (no treatment); ${ }^{\#} \mathrm{P}<0.05$ vs. $150 \mathrm{ng} / \mathrm{ml}$ visfatin. Values represent the means \pm standard deviation.

that the pro-apototic effects were inhibited by pre-treatment with FK866, a visfatin inhibitor.

The number of EPCs in the blood circulation are regarded as an indicator of endothelial function and cardiovascular disease prognosis (20). Following vessel impairment and tissue ischemia, EPCs can originate from the bone marrow and home into ischemic locations where they participate in the re-endothelialization of impaired blood vessels (13). Therefore, EPCs play an important role in maintaining the completeness of endothelial structure and the normal function of the vascular endothelium. Several chronic factors have been implicated in mediating the apoptosis and dysfunction of EPCs, such as gluco-lipotoxicity, hyperglycemia, hyperlipidemia and oxidative stress (21). Apoptosis is a multi-step process and an increasing number of genes have been identified to be involved in the control or execution of apoptosis (22). There are two major pathways through which apoptosis occurs; the extrinsic pathway and the intrinsic pathway (23). Although these two pathways may act independently of each other, they converge at the level of caspase-3. As the most important member of the caspase-family, caspase-3 is responsible for many biochemical mechanisms driving apoptosis that lead to the cleavage of nuclear and cytosolic material, chromatin condensation, fragmentation of DNA, and disassembly into membrane-enclosed vesicles (24). Apoptosis is also regulated by members of the Bcl-2 family of genes (25), with the effect of the anti-apoptotic 
gene, $\mathrm{Bcl}-2$, counteracted by the pro-apoptotic gene, Bax. Indeed, the balance between these opposing genes may be the key determinant of cell survival by regulating the apoptotic process, whereby an increase in the $\mathrm{Bax} / \mathrm{Bcl}-2$ ratio leads to the activation of caspase- 3 , and thus determines a cell's susceptibility to undergo apoptosis $(25,26)$. Therefore, we detected the expression of apoptosis-related proteins in this study.

In this study, following treatment with visfatin, we detected decreased levels of the anti-apoptotic gene, Bcl-2, and increased expression levels of the pro-apoptotic gene, caspase-3, as well as an increased $\mathrm{Bax} / \mathrm{Bcl}-2$ ratio; all these effects were inhibited by FK866. This finding suggests that visfatin regulates the expression of Bax/Bcl-2/caspase-3 in the process of EPC death, which may explain, at least in part, the decreased number of EPCs.

Due to its role in inflammation, visfatin has been implicated in the pathogenesis of various metabolic disorders, such as metabolic syndrome, type 2 diabetes mellitus and obesity $(6,7,27)$. Our previous studies also revealed that visfatin treatment impaired the migration and adhesion capacity of EPCs (19). A possible mechanism through which visfatin exerts these effects lies in the inflammation induced by visfatin, which may upregulate a series of inflammatory factors, leading to the apoptosis of EPCs and resulted in the reduction of their number and function (19). Inflammation in EPCs has also been linked to pro-inflammatory adhesion molecules, which can be inducers of leukocyte recruitment (28). Vascular inflammation is a common feature of vascular damage in a number of diseases and is a complex process that is initiated by activation of the immune system, leading to the increased expression of pro-inflammatory cytokines $(29,30)$. Previous studies have shown that IL-6 is a potent pro-inflammatory cytokine involved in a number of pathological processes of vascular inflammation and injury, such as proliferative diabetic retinopathy and atherosclerosis, while IL-6 blockade can result in the prevention or therapeutic suppression of disease development (31-34). ICAM-1 is linked to the development of atherosclerosis and is well characterized for its roles in cell adhesion and actin polymerization processes $(35,36)$. In addition, both IL- 6 and ICAM-1 can be stimulated by the activation of the NF- $\mathrm{NB}$ signaling pathway $(37,38)$.

In this study, we found that visfatin enhanced the protein expression of ICAM-1 and IL- 6 in the EPCs, and that this effect was inhibited by pre-treatment with FK866 or BAY11-7085. These results suggest that in cultured EPCs, the synthesis of IL- 6 and ICAM-1 is modulated by visfatin, and our data in agreement with those of a previous study, showing that visfatin enhances the expression of adhesion molecules (ICAM-1 and VCAM-1), as well as that of other inflammatory mediators through NF- $\kappa \mathrm{B}$ activation in human endothelial cells (38). We also found that treatment with visfatin increased the expression of NF- $\mathrm{NB}$ in the EPCs in a dose-dependent manner at both the mRNA and protein level. Given the regulatory effects of visfatin on Bcl-2/Bax/caspase-3, the present data showing that pre-treatment with the inhibitors, FK866 or BAY11-7085, effectively suppressed visfatin-induced apoptosis, as well as ICAM-1 and IL-6 protein expression, support the notion that $\mathrm{NF}-\kappa \mathrm{B}$ in part mediates visfatin-induced apoptosis. Taken together, the present data suggest that visfatin is an influential upstream factor inducing inflammation and the apoptosis of EPCs, and that its activity results in decreased quantities of
EPCs via the upregulation of $\mathrm{NF}-\kappa \mathrm{B}$. These findings are in line with those of previous studies demonstrating the involvement of NF- $\kappa \mathrm{B}$ in endothelial cell dysfunction and impaired angiogenesis $(38,39)$.

It has previously been reported that FK866 attenuates inflammatory responses and cellular apoptosis following organ injury, ultimately leading to improved cell survival by inhibiting NF- $\kappa \mathrm{B}$ activation (40). As FK866 is a specific inhibitor of visfatin, it is reasonable to speculate that visfatin induces apoptosis, at least in part, through $\mathrm{NF}-\kappa \mathrm{B}$ activation.

However, different cells show different responses following visfatin stimulation. Patel et al (41) demonstrated that the exogenous expression of visfatin in PC3 prostate cancer cells increased tumor cell proliferation and the expression of matrix metalloproteinase (MMP)-2/9 at the molecular level. Yang et al (42) generated stable cell lines from fibrosarcoma HT1080 and 293 cells which overexpress human visfatin protein and stable cell lines with visfatin knockdown using siRNA, and found that the stable visfatin-overexpressing cells were substantially more resistant to apoptosis induced by methylmethane sulfonate (MMS) than the control. FK866 also activates the apoptotic cascade in cancer cells with the release of cytochrome $c$ and the activation of caspase-3 $(43,44)$. In addition, differences in metabolism have been noted between normal cells and cancer cells (45). The different metabolic pathways that cancer cells utilize to survive and proliferate under stress environments (46) may be explained by the discrepancy between normal cells and cancer cells in response to visfatin and FK866.

Furthermore, the effect of visfatin seems also to rely on dosage and the state of cellular activation. On the one hand, circulating visfatin induces the cellular expression of inflammatory cytokines, such as tumor necrosis factor- $\alpha$ (TNF- $\alpha$ ), IL-8, IL-6 and MMP-9 by activating the p38-MAPK signaling pathway $(47,48)$, in accordance with our data on EPCs, whereby IL-6 was prominently upregulated by visfatin. On the other hand, other studies have suggested that higher concentrations of visfatin result in the upregulation of anti-inflammatory mediators, such as IL-10 and IL-1 receptor antagonists $(9,11)$. It is known that visfatin has dual functions in that it acts extracellularly as a pro-inflammatory cytokine and intracellularly as an enzyme catalyzing the rate-limiting step of the NAD salvage pathway from nicotinamide. Specifically, Rongvaux et al (49) demonstrated that visfatin, as an enzyme catalyzing the condensation of nicotinamide with phosphoribosyl pyrophosphate, participated in cellular resistance to genotoxic or oxidative stress, and it conferred to cells of the immune system the ability to survive during stressful situations. In addition, visfatin enables proliferating human endothelial cells to resist the oxidative stress indcued by high glucose, and to productively utilize excess glucose to support replicative longevity and angiogenic activity via SIRT1 (50), while it also induces angiogenesis via the MAPK and PI3K/Akt signaling pathways (51). The reason for such discrepancies in the published findings surrounding visfatin is unclear. The doses and species used or exposure times are different among the studies and may have an effect that generates the different results.

To date, the mechanisms of action of visfatin as a cytokine remain unclear and numerous questions remain to be answered. However, our data indicate that visfatin induces EPC apoptosis 
by increasing the expression of pro-inflammatory mediators partly through the regulation of NF- $\kappa \mathrm{B}$. To fully understand the physiological machanism of visfatin and given the clear importance of this molecule to several physiological and pathological processes, further research is required.

\section{Acknowledgements}

This study was supported by grants from the Hebei Natural Science Foundation of China (no. H2014307035). We are indebted to Chao Wang, Hanying Xing, Zhihua Wang and Jingci Yang for assistance and technical advice.

\section{References}

1. Samal B, Sun Y, Stearns G, Xie C, Suggs S and McNiece I Cloning and characterization of the cDNA encoding a novel human pre-B-cell colony-enhancing factor. Mol Cell Biol 14: 1431-1437, 1994.

2. Garten A, Petzold S, Schuster S, Körner A, Kratzsch J and Kiess W: Nampt and its potential role in inflammation and type 2 diabetes. Handb Exp Pharmacol 203: 147-164, 2011.

3. Kadoglou NP, Sailer N, Moumtzouoglou A, Kapelouzou A, Tsanikidis H, Vitta I, Karkos C, Karayannacos PE, Gerasimidis T and Liapis CD: Visfatin (nampt) and ghrelin as novel markers of carotid atherosclerosis in patients with type 2 diabetes. Exp Clin Endocrinol Diabetes 118: 75-80, 2010.

4. Iacobellis G, Iorio M, Napoli N, Cotesta D, Zinnamosca L, Marinelli C, Petramala L, Minisola S, D'Erasmo E and Letizia C: Relation of adiponectin, visfatin and bone mineral density in patients with metabolic syndrome. J Endocrinol Invest 34: e12-e15, 2011.

5. Unlütürk U, Harmanci A, Yildiz BO and Bayraktar M: Dynamics of Nampt/visfatin and high molecular weight adiponectin in response to oral glucose load in obese and lean women. Clin Endocrinol (Oxf) 72: 469-474, 2010.

6. de Luis DA, Aller R, Gonzalez Sagrado M, Conde R, Izaola O and de la Fuente B: Serum visfatin levels and metabolic syndrome criteria in obese female subjects. Diabetes Metab Res Rev 29: 576-581, 2013.

7. Chen S, Sun L, Gao H, Ren L, Liu N and Song G: Visfatin and oxidative stress influence endothelial progenitor cells in obese populations. Endocr Res 40: 83-87, 2015.

8. Boini KM, Zhang C, Xia M, Han WQ, Brimson C, Poklis JL and Li PL: Visfatin-induced lipid raft redox signaling platforms and dysfunction in glomerular endothelial cells. Biochim Biophys Acta 1801: 1294-1304, 2010.

9. Xiao K, Zou WH, Yang Z, Zia ur Rehman, Ansari AR, Yuan HR, Zhou Y, Cui L, Peng KM and Song H: The role of visfatin on the regulation of inflammation and apoptosis in the spleen of LPS-treated rats. Cell Tissue Res 359: 605-618, 2015.

10. van der Veer E, Nong Z, O'Neil C, Urquhart B, Freeman D and Pickering JG: Pre-B-cell colony-enhancing factor regulates $\mathrm{NAD}^{+}$-dependent protein deacetylase activity and promotes vascular smooth muscle cell maturation. Circ Res 97: 25-34, 2005.

11. Moschen AR, Kaser A, Enrich B, Mosheimer B, Theurl M, Niederegger $\mathrm{H}$ and Tilg $\mathrm{H}$ : Visfatin, an adipocytokine with proinflammatory and immunomodulating properties. J Immunol 178: $1748-1758,2007$.

12. Vallejo S, Romacho T, Angulo J, Villalobos LA, Cercas E, Leivas A, Bermejo E, Carraro R, Sánchez-Ferrer CF and Peiró C: Visfatin impairs endothelium-dependent relaxation in rat and human mesenteric microvessels through nicotinamide phosphoribosyltransferase activity. PLoS One 6: e27299, 2011.

13. Urbich $\mathrm{C}$ and Dimmeler S: Endothelial progenitor cells: Characterization and role in vascular biology. Circ Res 95: 343-353, 2004.

14. Schmidt-Lucke C, Rössig L, Fichtlscherer S, Vasa M, Britten M, Kämper U, Dimmeler S and Zeiher AM: Reduced number of circulating endothelial progenitor cells predicts future cardiovascular events: Proof of concept for the clinical importance of endogenous vascular repair. Circulation 111: 2981-2987, 2005.

15. Werner N, Kosiol S, Schiegl T, Ahlers P, Walenta K, Link A, Böhm M and Nickenig G: Circulating endothelial progenitor cells and cardiovascular outcomes. N Engl J Med 353: 999-1007, 2005.
16. Denny MF, Thacker S, Mehta H, Somers EC, Dodick T, Barrat FJ, McCune WJ and Kaplan MJ: Interferon-alpha promotes abnormal vasculogenesis in lupus: A potential pathway for premature atherosclerosis. Blood 110: 2907-2915, 2007.

17. Fujii H, Li SH, Szmitko PE, Fedak PW and Verma S: C-reactive protein alters antioxidant defenses and promotes apoptosis in endothelial progenitor cells. Arterioscler Thromb Vasc Biol 26: 2476-2482, 2006.

18. Tie G, Yan J, Yang Y, Park BD, Messina JA, Raffai RL, Nowicki PT and Messina LM: Oxidized low-density lipoprotein induces apoptosis in endothelial progenitor cells by inactivating the phosphoinositide 3-kinase/Akt pathway. J Vasc Res 47: 519-530, 2010.

19. Sun Y, Chen S, Song G, Ren L, Wei L, Liu N, Zhang D and Lv X: Effect of visfatin on the function of endothelial progenitor cells in high-fat-fed obese rats and investigation of its mechanism of action. Int J Mol Med 30: 622-628, 2012.

20. Bakogiannis C, Tousoulis D, Androulakis E, Briasoulis A, Papageorgiou N, Vogiatzi G, Kampoli AM, Charakida M, Siasos G, Latsios G, et al: Circulating endothelial progenitor cells as biomarkers for prediction of cardiovascular outcomes. Curr Med Chem 19: 2597-2604, 2012.

21. Peng J, Liu B, Ma QL and Luo XJ: Dysfunctional endothelial progenitor cells in cardiovascular diseases: Role of NADPH oxidase. J Cardiovasc Pharmacol 65: 80-87, 2015.

22. Joseph B, Marchetti P, Formstecher P, Kroemer G, Lewensohn R and Zhivotovsky B: Mitochondrial dysfunction is an essential step for killing of non-small cell lung carcinomas resistant to conventional treatment. Oncogene 21: 65-77, 2002.

23. Ghobrial IM, Witzig TE and Adjei AA: Targeting apoptosis pathways in cancer therapy. CA Cancer J Clin 55: 178-194, 2005.

24. Salvesen GS and Dixit VM: Caspases: Intracellular signaling by proteolysis. Cell 91: 443-446, 1997.

25. Korsmeyer SJ: BCL-2 gene family and the regulation of programmed cell death. Cancer Res 59 (Suppl 7): 1693s-1700s, 1999.

26. Youle RJ and Strasser A: The BCL-2 protein family: Opposing activities that mediate cell death. Nat Rev Mol Cell Biol 9: 47-59, 2008.

27. Laudes M, Oberhauser F, Schulte DM, Freude S, Bilkovski R, Mauer J, Rappl G, Abken H, Hahn M, Schulz O, et al: Visfatin/PBEF/Nampt and resistin expressions in circulating blood monocytes are differentially related to obesity and type 2 diabetes in humans. Horm Metab Res 42: 268-273, 2010.

28. Zhang Y, Ingram DA, Murphy MP, Saadatzadeh MR, Mead LE, Prater DN and Rehman J: Release of proinflammatory mediators and expression of proinflammatory adhesion molecules by endothelial progenitor cells. Am J Physiol Heart Circ Physiol 296: H1675-H1682, 2009.

29. Adamis AP and Berman AJ: Immunological mechanisms in the pathogenesis of diabetic retinopathy. Semin Immunopathol 30: 65-84, 2008.

30. Satofuka S, Ichihara A, Nagai N, Yamashiro K, Koto T, Shinoda H, Noda K, Ozawa Y, Inoue M, Tsubota K, et al: Suppression of ocular inflammation in endotoxin-induced uveitis by inhibiting nonproteolytic activation of prorenin. Invest Ophthalmol Vis Sci 47: 2686-2692, 2006.

31. MurugeswariP,ShuklaD, Rajendran A,KimR,NamperumalsamyP and Muthukkaruppan V: Proinflammatory cytokines and angiogenic and anti-angiogenic factors in vitreous of patients with proliferative diabetic retinopathy and eales' disease. Retina 28: 817-824, 2008.

32. Tang JN, Shen DL, Liu CL, Wang XF, Zhang L, Xuan XX, Cui LL and Zhang JY: Plasma levels of Clq/TNF-related protein 1 and interleukin 6 in patients with acute coronary syndrome or stable angina pectoris. Am J Med Sci 349: 130-136, 2015.

33. Kitaba S, Murota H, Terao M, Azukizawa H, Terabe F, Shima Y, Fujimoto M, Tanaka T, Naka T, Kishimoto T, et al: Blockade of interleukin-6 receptor alleviates disease in mouse model of scleroderma. Am J Pathol 180: 165-176, 2012.

34. Okiyama N, Sugihara T, Iwakura Y, Yokozeki H, Miyasaka N and Kohsaka H: Therapeutic effects of interleukin- 6 blockade in a murine model of polymyositis that does not require interleukin-17A. Arthritis Rheum 60: 2505-2512, 2009.

35. Kitagawa K, Matsumoto M, Sasaki T, Hashimoto H, Kuwabara K, Ohtsuki T and Hori M: Involvement of ICAM-1 in the progression of atherosclerosis in APOE-knockout mice. Atherosclerosis 160: 305-310, 2002 . 
36. Bielinski SJ, Pankow JS, Li N, Hsu FC, Adar SD, Jenny NS, Bowden DW, Wasserman BA and Arnett D: ICAM1 and VCAM1 polymorphisms, coronary artery calcium, and circulating levels of soluble ICAM-1: the multi-ethnic study of atherosclerosis (MESA). Atherosclerosis 201: 339-344, 2008.

37. Tanaka T, Narazaki M and Kishimoto T: IL-6 in inflammation, immunity, and disease. Cold Spring Harb Perspect Biol 6: a016295, 2014.

38. Kim SR, Bae YH, Bae SK, Choi KS, Yoon KH, Koo TH, Jang HO, Yun I, Kim KW, Kwon YG, et al: Visfatin enhances ICAM-1 and VCAM-1 expression through ROS-dependent NF-kappaB activation in endothelial cells. Biochim Biophys Acta 1783: 886-895, 2008.

39. Wan R, Liu Y, Li L, Zhu C, Jin L and Li S: Urocortin increased endothelial ICAM1 by cPLA2-dependent NF-kappaB and PKA pathways in HUVECs. J Mol Endocrinol 52: 43-53, 2013.

40. Matsuda A, Yang WL, Jacob A, Aziz M, Matsuo S, Matsutani T, Uchida E and Wang P: FK866, a visfatin inhibitor, protects against acute lung injury after intestinal ischemia-reperfusion in mice via NF-кB pathway. Ann Surg 259: 1007-1017, 2014.

41. Patel ST, Mistry T, Brown JE, Digby JE, Adya R, Desai KM and Randeva HS: A novel role for the adipokine visfatin/pre-B cell colony-enhancing factor 1 in prostate carcinogenesis. Peptides 31: 51-57, 2010.

42. Yang H, Yang T, Baur JA, Perez E, Matsui T, Carmona JJ, Lamming DW, Souza-Pinto NC, Bohr VA, Rosenzweig A, et al: Nutrient-sensitive mitochondrial $\mathrm{NAD}^{+}$levels dictate cell survival. Cell 130: 1095-1107, 2007.

43. Hasmann M and Schemainda I: FK866, a highly specific noncompetitive inhibitor of nicotinamide phosphoribosyltransferase, represents a novel mechanism for induction of tumor cell apoptosis. Cancer Res 63: 7436-7442, 2003.

44. Wosikowski K, Mattern K, Schemainda I, Hasmann M, Rattel B and Löser R: WK175, a novel antitumor agent, decreases the intracellular nicotinamide adenine dinucleotide concentration and induces the apoptotic cascade in human leukemia cells. Cancer Res 62: 1057-1062, 2002.
45. Crabtree HG: Observations on the carbohydrate metabolism of tumours. Biochem J 23: 536-545, 1929.

46. Kroemer G and Pouyssegur J: Tumor cell metabolism: Cancer's Achilles' heel. Cancer Cell 13: 472-482, 2008.

47. Tan BK, Chen J, Digby JE, Keay SD, Kennedy CR and Randeva HS: Increased visfatin messenger ribonucleic acid and protein levels in adipose tissue and adipocytes in women with polycystic ovary syndrome: Parallel increase in plasma visfatin. J Clin Endocrinol Metab 91: 5022-5028, 2006.

48. Kocelak P, Olszanecka-Glinianowicz M, Owczarek A, Bożentowicz-Wikarek M, Brzozowska A, Mossakowska M, Zdrojewski T, Grodzicki T, Więcek A and Chudek J: Plasma visfatin/nicotinamide phosphoribosyltransferase levels in hypertensive elderly - results from the PolSenior substudy. J Am Soc Hypertens 9: 1-8, 2015.

49. Rongvaux A, Galli M, Denanglaire S, Van Gool F, Drèze PL, Szpirer C, Bureau F, Andris F and Leo O: Nicotinamide phosphoribosyl transferase/pre-B cell colony-enhancing factor/visfatin is required for lymphocyte development and cellular resistance to genotoxic stress. J Immunol : 4685-4695, 2008.

50. Borradaile NM and Pickering JG: Nicotinamide phosphoribosyltransferase imparts human endothelial cells with extended replicative lifespan and enhanced angiogenic capacity in a high glucose environment. Aging Cell 8: 100-112, 2009.

51. Adya R, Tan BK, Punn A, Chen J and Randeva HS: Visfatin induces human endothelial VEGF and MMP-2/9 production via MAPK and PI3K/Akt signalling pathways: Novel insights into visfatin-induced angiogenesis. Cardiovasc Res 78: 356-365, 2008. 